\title{
Assesing The Ability Of Critical Thinking Among Students Of Medical And Dental Colleges Around Hyderabad: A Cross Sectional Study
}

Research Article

\author{
Dr. Tejaswi Kala ${ }^{1}$, Mr Maddhireddy Saathvik², Dr. Ganesh Kulkarni ${ }^{3}$, Dr. Hariprasad Gone ${ }^{4 *}$
}

${ }^{1}$ Senior Lecturer, Department of Public Health Dentsitry, Tirumala institute of Dental Sciences, Nizamabad,Telangana, India.

${ }^{2}$ Statistics, C/o Dr Sridhar International Dental hospitals, Kukatpally, Hyderabad, Telangana, India.

${ }^{3}$ Professor, Department of Oral Pathology, Malla Reddy Institute of Dental Sciences, Jeedimetla, Hyderabad-500055, Telangana, India.

${ }^{4}$ Senior Lecturer, Department of Public Health Dentistry, Malla Reddy Institute of Dental Sciences, Jeedimetla, Hyderabad-500055, Telangana, India.

\section{Abstract}

Objective: To assess critical thinking ability in medical and dental students, as well as to compare critical thinking ability between medical and dental students.

Method: A cross sectional study was carried on among 300 medical and 300 dental students from Hyderabad city, Telangana. Distribution of sample in three medical and three dental colleges around Hyderabad city. A sample of 600 study participants were selected. This was done by selecting three medical and three dental colleges by lottery method from the list of total colleges around Hyderabad city.A predesigned proforma was used for assessing the critical thinking ability. The proforma consisted of demographic data which was common for both (Name, age, gender, type of schooling, academic year, father's annual income and residential address) and the Watson - Glaser's critical thinking questionnaire was used to assess the critical thinking ability. The purpose of the study was clearly explained to all the subjects. Collected data was subjected to statistical analysis. Results: The association amongthe dental and medical studentswere found to be $7.8 \pm 1.8$ and $8.1 \pm 2$ respectively when the means of their total scores were compared. There was statistically significant difference found among the dental and medical students. $(p=0.01)$. The means of total scores among female and male students were found to be $7.8 \pm 1.7$ and $8.5 \pm 2$ respectively. There was statistically significant difference found among the female and male students. $(\mathrm{p}=0.01)$.

Conclusion: The research indicates that medical students have a higher level of critical thinking than dentistry students. Since the body of information in biomedical and biomaterial sciences continues to expand rapidly, critical thinking becomes more important, as it places a premium on logic over emotion. It is critical prior to implementing any technique in clinical practice.

Keywords: Cross-Sectional Studies; Thinking, Students.

\section{Introduction}

Critical thinking is generallyrecognized educational objective. Its definition is contentious, but it is regarded as varying interpretations of the same fundamental concept: goal-directed thinking. Conceptions vary in their scope, purpose, criteria and standards for thinking deliberately, and the cognitive components they concentrate on. Its acceptance as an educational goal is supported by respect for students' autonomy and preparation for life success and democratic citizenship. They have the attitudes and skills to think critically when necessary. We can assess talents directly and dispositions indirectly by examining what circumstances help or hinder the practice of abilities. Standardized tests have been cre- ated to measure these inclinations and skills. Experimentally, educational intervention that involves dialogue, anchored instruction, and mentorship improves them.

There have been debates over the generalizability of critical thinking across domains, about claimed bias in critical thinking theories and training, and about the connection between critical thinking and other types of thinking. According to Bailin et al. (1999b), if one examines the types of thinking that educators regard not to be critical thinking and the types that educators consider to be critical thinking, one can infer that educators generally see critical thinking as having at least three characteristics. It is done in order to form an opinion on what to think or do. The individual who

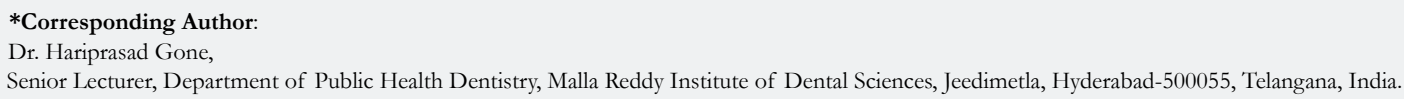

Copyright: Dr. Hariprasad Gone ${ }^{\top} 2021$. This is an open-access article distributed under the terms of the Creative Commons Attribution License, which permits unrestricted use, distribution and reproduction in any medium, provided the original author and source are credited. 
is thinking is attempting to meet acceptable criteria of sufficiency and correctness. The reasoning satisfies the necessary criteria up to a certain point.

One might summarise the fundamental idea entailing these three characteristics as follows: critical thinking is deliberate goal-directed thinking. Generally, conceptualizations of critical thinking do not include moral integrity as a component. There is disagreement about whether standardised exams or multiple-choice questions can adequately evaluate critical thinking. It has been suggested that effective evaluation of critical thinking abilities should be a continuous and cumulative process that is open-ended and incorporates self-assessment. Additionally, some have suggested that since critical thinking is a process rather than an end, employing outcome measurements at a certain moment in time may be inadequate. Nonetheless, there is an acknowledgement that the time, skill, and resources necessary to create reliable and accurate measures of critical thinking demand the use of standardised testing. Educators are thus tasked with the responsibility of teaching and evaluating critical thinking competency in the absence of a consensual definition, an agreement on how it can be taught, and insufficient evidence to support the reliability, validity, and usefulness of existing assessment methods.[1]

Critical thinking is generally acknowledged as a necessary skill for dentistry . Indeed, the American Dental Education Association (ADEA) ranks critical thinking as the first domain of entry-level competencies for beginning general dentists.[2] Similarly, the Commission on Dental Accreditation (CODA) requires dental school graduates to be "competent in the use of critical thinking," with the intent that the educational programme implement "methods that support the development of critical thinking and problem solving skills"[3]. Medicine [4], nursing [5], and pharmacy [6] are among the other health professions that have established criteria that are analogous to these.Health care practitioners must make clinical assessments quickly and accurately while using sound judgement and analytical skills. [7] As a result, critical thinking ability is important for providing health care that fulfils the requirements of patients while taking their context and preferences into account. Additionally, evidence-based medicine and dentistry must be implemented to optimise resource utilisation and provide high-quality care.[8] Thus, the purpose of this study was to assess critical thinking ability in medical and dental students, as well as to compare critical thinking ability between medical and dental students.

\section{Methodology}

A cross sectional study was carried on among 300 medical and 300 dental students from Hyderabad city, Telangana.

Study Population: The study comprised of 300 medical and 300 dental students from Hyderabad city, Telangana. STUDY DESIGN - This was a cross sectional, observational study conducted among 300 medical and 300 dental students from Hyderabad city, Telangana. Details of the Pilot study A Pilot study was carried out on a sample of 30 subjects in a dental college to check the feasibility of the survey, to note any difficulties encountered during the examination Watson - Glaser's critical thinking questionnaire was used to assess the critical thinking ability of under graduates and post graduates of medical and dental colleges. This questionnaire has five domains, they are Inference, Recognition of Assumptions, Deduction, Interpretation and Evaluation of Arguments. How well one can draw conclusions from facts? It assesses the ability to make judgements based on limited information. One has to decide whether a follow-on statement is true based on a prior statement The participants in the pilot study were not included in the final study. After the pilot study, the results were discussed with the head of the department professor and after going through the literature it was found that there is real necessity to conduct a study in this field which is untouched. Based on the results of the pilot study a statistician was consulted and sample size was calculated.

Sample Size Estimation The sample size was estimated based on the results obtained through the pilot study. The sample size was estimated to be 300 medical and 300 dental students. Mean = $7.2+1.5$ Confidence interval $=95 \%$ Error of mean $=5 \%$ The sample size was determined using the following formula , $\mathrm{N}=$ $(\mathrm{Z} \alpha / 2) 2 \sigma 2 / \mathrm{E} 2$

From the above formula the sample size of 284 was calculated which was rounded off to 300 So this made 300 medical and 300 dental students

\section{Organization Of The Survey}

Ethical clearance : The Ethical clearance was taken from the institutional review board of Sri Sai College of Dental Surgery, Vikarabad. Permission from the concerned authorities of the three medical and dental colleges was taken to collect the information from the students. Informed consent Voluntary informed consent was obtained from all the study participants before participating in the study after discussing in detail about the purpose of the study.

Schedule of the study: The study was systematically scheduled to spread over a period of two months from November 2018 to December 2018. Even though a detailed schedule plan was prepared well in advance, few adjustments and changes had to be made while working it out practically.

Sample distribution: Distribution of sample in three medical and three dental colleges around Hyderabad city. A sample of 600 study participants were selected. This was done by selecting three medical and three dental colleges by lottery method from the list of total colleges around Hyderabad city. The medical colleges included in the study were Mala Reddy Medical College, Bhaskara Medical College and Kamineni Institute of Medical Sciences. The three dental colleges included in the study were Sri Sai College of Dental Surgery, MNR college of Dental Sciences and Paniniya institute of dental sciences. 100 participants from three medical and three dental colleges around Hyderabad were recruited in the study. COLLECTION OF DATA MEASURES [1] Background Information Form The background information obtained from the students included name, age, gender, type of schooling, academic year, father's annual income and residential address. [2] The Watson - Glaser's critical thinking questionnaire evaluates a candidate's critical thinking ability in five separate areas: inferences, assumptions, deductions, interpretations and evaluation of arguments. Each of these skills is tested separately and there are therefore five different types of questions in the this. 
Materials and Armamentarium: The following instruments were used in the study 1. Questionnaire 2. Writing pad 3. Pen

Procedure: A predesigned proforma was used for assessing the critical thinking ability. The proforma consisted of demographic data which was common for both (Name, age, gender, type of schooling, academic year, father's annual income and residential address) and the Watson - Glaser's critical thinking questionnaire was used to assess the critical thinking ability. The purpose of the study was clearly explained to all the subjects. The information from the study participants was collected by the examiner in the form of self-assessment examination. The study participants were clearly explained regarding the Watson - Glaser's critical thinking questionnaire that one's own knowledge must be disregarded, general knowledge is not being tested here and the decision must be based $100 \%$ on the first statement.

\section{Statistical Analysis}

The collected data was entered in to Microsoft excel 2016 and subjected to statistical analysis using statistical package for social sciences (SPSS version 20.0). The statistical tests used were STUDENT'S T-TEST and CHI- SQUARE TEST.

\section{Results}

Table 1 describes the demographic details of the study population. Majority of the participants were females among both dental and medical students i.e $83 \%$ and $78 \%$ respectively. Only $17 \%$ and $22 \%$ were males among them in dental and medical students respectively.

Most of them pursued their secondary education from SSC schools i.e $86 \%$ and $87 \%$ respectively among both dental and medical students. While $10 \%$ and $11 \%$ of study participants pursued their secondary education from CBSE schools respectively among both dental and medical students.A major number of study participants were belonging to third year with $20 \%$ in both dental and medical study participants followed by interns i.e. $16 \%$ and $17 \%$ respectively in dental and medical study participants.Majority of the participants were residing in urban area among both dental and medical students i.e $88 \%$ and $86 \%$ respectively. Only $12 \%$ and $14 \%$ were residing in rural area among them in dental and medical students respectively.

Table 3 describes the distribution of scores of Watson and Glaser's critical thinking questionnaire among dental and medical students. Maximum score of assumption was found to be 4 and minimum was found to be 0 in both dental and medical participants while maximum and minimum scores of inference, deduction, interpretation and argument were found to be 3 and 0 respectively. Maximum and minimum total scores of dental and medical students were 13, 2 and 14, 2 respectively.

Table 4 describes the association between scores of Watson and Glaser's critical thinking questionnaire among dental and medical students. The means of total scores among dental and medical students were found to be $7.8 \pm 1.8$ and $8.1 \pm 2$ respectively. There was statistically significant difference found among the dental and medical students. $(\mathrm{p}=0.01)$

Table 5 describes the association between scores of Watson and Glaser's critical thinking questionnaire among female and male students. The means of total scores among female and male students were found to be $7.8 \pm 1.7$ and $8.5 \pm 2$ respectively. There was statistically significant difference found among the female and male students. $(\mathrm{p}=0.01)$

\section{Discussion}

Critical thinking is the process of analysing information in order to make a decision. The topic is complicated, and many

Table 1. Distribution of participants based on their demographic details.

\begin{tabular}{|c|c|c|c|c|c|}
\hline & \multicolumn{2}{|c|}{ Dental } & \multicolumn{2}{c|}{ Medical } \\
\hline Demographic details & Frequency & Percentage & Frequency & Percentage \\
\hline Gender & Female & 250 & 83.3 & 235 & 78.3 \\
\cline { 2 - 6 } & Male & 50 & 16.7 & 65 & 21.7 \\
\hline Schooling & SSC & 259 & 86.3 & 262 & 87.3 \\
\cline { 2 - 6 } & CBSE & 31 & 10.3 & 33 & 11 \\
\cline { 2 - 6 } & ICSE & 10 & 3.3 & 5 & 1.7 \\
\hline \multirow{4}{*}{$\begin{array}{c}\text { Year of } \\
\text { study }\end{array}$} & 1styear & 36 & 12 & 35 & 11.7 \\
\cline { 2 - 6 } & 2ndyear & 36 & 12 & 26 & 8.7 \\
\cline { 2 - 6 } & 3rdyear & 60 & 20 & 61 & 20.3 \\
\cline { 2 - 6 } & 4thyear & 30 & 10 & 30 & 10 \\
\cline { 2 - 6 } & Intern & 48 & 16 & 51 & 17 \\
\cline { 2 - 6 } & 1st year PG & 36 & 12 & 38 & 12.7 \\
\cline { 2 - 6 } & 2nd year PG & 30 & 10 & 32 & 10.7 \\
\cline { 2 - 6 } & 3rd year PG & 24 & 8 & 27 & 9 \\
\hline \multirow{7}{*}{ Residence } & Urban & 264 & 88 & 259 & 86.3 \\
\cline { 2 - 6 } & Rural & 36 & 12 & 41 & 13.7 \\
\hline \multicolumn{2}{|c|}{ Total } & 300 & 100 & 300 & 100 \\
\hline
\end{tabular}


Table 2. Distribution of participants based on Watson and Glaser's criticalt hinking scores.

\begin{tabular}{|c|c|c|c|c|}
\hline \multirow{2}{*}{ Gender } & \multicolumn{2}{|c|}{ Dental } & \multicolumn{2}{c|}{ Medical } \\
\cline { 2 - 5 } & Frequency & Percentage & Frequency & Percentage \\
\hline HIGH & 178 & 59.3 & 188 & 62.6 \\
\hline LOW & 122 & 40.7 & 112 & 37.4 \\
\hline Total & 300 & 100 & 300 & 100 \\
\hline
\end{tabular}

Table 3. Distribution of scores of Watson and Glaser's critical thinking questionnaire among dental and medical students.

\begin{tabular}{|c|c|c|c|c|c|c|c|c|}
\hline \multirow{2}{*}{$\begin{array}{c}\text { W \&G } \\
\text { Questionnaire }\end{array}$} & \multicolumn{4}{|c|}{ Dental } & \multicolumn{4}{c|}{ Medical } \\
\cline { 2 - 10 } & Mini. & Max. & Mean & S.D & Mini. & Max. & Mean & S.D \\
\hline Inference & 0 & 3 & 0.59 & 0.71 & 0 & 3 & 0.96 & 0.893 \\
\hline Assumption & 0 & 4 & 2.32 & 0.86 & 0 & 4 & 2.32 & 0.863 \\
\hline Deduction & 0 & 3 & 1.48 & 0.799 & 0 & 3 & 1.48 & 0.799 \\
\hline Interpretation & 0 & 3 & 1.63 & 0.797 & 0 & 3 & 1.61 & 0.8 \\
\hline Argument & 0 & 3 & 1.69 & 0.708 & 0 & 3 & 1.72 & 0.734 \\
\hline Total & 2 & 13 & 7.77 & 1.737 & 2 & 14 & 8.12 & 1.984 \\
\hline
\end{tabular}

Table 4. Association between scores of Watson and Glaser's critical thinking questionnaire among dental and medical students.

\begin{tabular}{|c|c|c|c|c|c|c|c|}
\hline \multirow{2}{*}{$\begin{array}{c}\text { W \&G } \\
\text { Questionnaire }\end{array}$} & \multicolumn{3}{|c|}{ Dental } & \multicolumn{3}{c|}{ Medical } & \multirow{2}{*}{ Pvalue } \\
\cline { 2 - 8 } & $\mathbf{N}$ & Mean & S.D & N & Mean & S.D & \\
\hline Inference & 300 & 0.59 & 0.71 & 300 & 0.96 & 0.893 & $<0.001 *(\mathrm{~S})$ \\
\hline Assumption & 300 & 2.32 & 0.86 & 300 & 2.32 & 0.863 & $0.96(\mathrm{NS})$ \\
\hline Deduction & 300 & 1.48 & 0.799 & 300 & 1.48 & 0.799 & $1(\mathrm{NS})$ \\
\hline Interpretation & 300 & 1.63 & 0.797 & 300 & 1.61 & 0.8 & $0.79(\mathrm{NS})$ \\
\hline Argument & 300 & 1.69 & 0.708 & 300 & 1.72 & 0.734 & $0.69(\mathrm{NS})$ \\
\hline Total & 300 & 7.77 & 1.737 & 300 & 8.12 & 1.984 & $0.01 *(\mathrm{~S})$ \\
\hline
\end{tabular}

Table 5. Association between scores of Watson and Glaser's critical thinking questionnaire among female and male students.

\begin{tabular}{|c|c|c|c|c|c|c|c|}
\hline \multirow{2}{*}{$\begin{array}{c}\text { W \&G } \\
\text { Questionnaire }\end{array}$} & \multicolumn{3}{|c|}{ Female } & \multicolumn{3}{c|}{ Male } & \multirow{2}{*}{ Pvalue } \\
\cline { 2 - 7 } & $\mathbf{N}$ & Mean & S.D & N & Mean & S.D & \\
\hline Inference & 485 & 0.74 & 0.812 & 115 & 0.91 & 0.874 & $0.04 *(\mathrm{~S})$ \\
\hline Assumption & 485 & 2.31 & 0.88 & 115 & 2.37 & 0.778 & $0.44(\mathrm{NS})$ \\
\hline Deduction & 485 & 1.45 & 0.795 & 115 & 1.57 & 0.806 & $0.14(\mathrm{NS})$ \\
\hline Interpretation & 485 & 1.58 & 0.779 & 115 & 1.78 & 0.856 & $0.01 *(\mathrm{~S})$ \\
\hline Argument & 485 & 1.68 & 0.718 & 115 & 1.82 & 0.72 & $0.06(\mathrm{NS})$ \\
\hline Total & 485 & 7.82 & 1.764 & 115 & 8.48 & 2.198 & $0.001 *(\mathrm{~S})$ \\
\hline
\end{tabular}

definitions exist, but the most common ones include the logical, sceptical, and neutral assessment or appraisal of factual data. Self-directed, self-disciplined, self-monitored, and self-corrective thinking are all characteristics of critical thinking. It necessitates agreement with strict criteria of excellence and a conscious command of their application. It requires strong communication and problem-solving skills, as well as a will to transcend egocentrism and sociocentrism. Quality patient care in health care services may be accomplished in the twenty-first century by delivering patientcentered care, working in multidisciplinary teams, implementing quality improvement, using data, and implementing evidencebased procedures. The current yearly data production pace is
16.3ZB, with a tenfold increase in global data expected by 2025 . Because the internet has democratised knowledge, we are in peril of having all the answers but not understanding what they mean. "Thought and Knowledge are Power" because knowledge is only effective when it is used correctly, and thought is only effective when it can draw on a vast and precise knowledge base. Health care providers must make clinical decisions quickly while using excellent judgement and analytical abilities while dealing with a range of health issues. As a result, critical thinking skills are required to offer health care that fulfils patients' requirements while taking into account their circumstances and preferences. Furthermore, evidence-based medicine and dentistry must be adopted in 
order to optimise resource utilisation and offer high-quality treatment.

As a result, the present research used Watson and Glaser's scale to evaluate critical thinking ability in medical students and dentistry students, as well as to compare critical thinking capacity across medical and dental students. The Watson Glaser critical thinking exam evaluates a person's ability to comprehend and comprehend events and information. It is often used by organisations that place a premium on the capacity to critically evaluate arguments or ideas. The Watson Glaser exam assesses a candidate's critical thinking abilities in five domains: inferences, assumptions, deductions, interpretations, and argument assessment. The Watson Glaser exam has five distinct kinds of questions since each of these abilities is evaluated individually. 1. Inferences: An inference is a conclusion reached after considering facts and reasoning. It allows for non-explicit inferences to be made. 2. Assumption: Something we take for granted is called an assumption. People make a lot of assumptions that aren't always true; being able to recognise them is an important part of critical thinking. 3. Deductions: A deduction is the drawing of a conclusion from a general rule or premise in a specific situation. However, such deductions may be erroneous at times. 4. Interpretation : An interpretation is a determination of whether or not a conclusion can be drawn logically from the data or evidence presented. This necessitates an individual's grasp of the exact meaning or importance of a piece of information, as well as the proper application of that knowledge. 5 . Argument Evaluation: This section tests your ability to assess the strength of an argument. Arguments may be powerful or weak, and in order to be strong, they must be significant and closely connected to the issue.

The present study's results indicated a favourable connection between students' critical thinking skills and their age. This may be because as individuals get older, they grow more mature and confident, and they become better prepared to think critically as they acquire more experience in different situations. The greatest critical thinking scores were discovered in younger pupils in a research by Shin et al, which contradicts the present study, while Jung DY's findings are in agreement with the current study. Females made up the bulk of the research participants $(80.8 \%)$, which may be attributed to females' greater interest in medical and dental areas than men'. However, males were shown to have higher critical thinking capacity than girls in this research, which may be owing to males in India being more exposed to social activities than women. Medical students' critical thinking scores were found to be somewhat higher than dentistry students'. This may be due to the fact that medical students are exposed to a wide range of situations as part of their extensive curriculum, which improves their critical thinking skills. The difference in reasoning between dental and medical students was the source of this simple discrepancy. This may be due to the fact that an inference is a conclusion based on facts and logic. It allows inferences to be made that aren't expressed directly. However, there are a variety of other possibilities. The issue with inferences is that they often lead to conclusions based on inadequate evidence, which may or may not be accurate. Critical thinking is the ability to evaluate information logically and rationally. Rather simply trusting the arguments and conclusions given, someone with good critical thinking skills would examine and attempt to comprehend the facts supplied. They will seek logical links between concepts, examine alternate interpretations of evidence, and assess the persuasiveness of given arguments.
Each person is born with some degree of subconscious prejudice in their thinking. Critical thinking skills may assist a person in overcoming these obstacles and distancing facts from beliefs. Students will be able to improve their cognitive abilities and eventually think more critically if they are exposed to evidence-based dentistry rather than being required to strictly adhere to procedure.

\section{Conclusion}

The research indicates that medical students have a higher level of critical thinking than dental students at the same time males were shown to have higher critical thinking capacity than girls in this research, which may be owing to males in India being more exposed to social activities than women. Since the body of information in biomedical and biomaterial sciences continues to expand rapidly, critical thinking becomes more important, as it places a premium on logic over emotion. It is critical prior to implementing any technique in clinical practise.

\section{References}

[1]. American Dental Education Association. ADEA competencies for the new general dentist. J Dent Educ 2017;81(7):844-7.

[2]. Commission on Dental Accreditation. Accreditation standards for dental education programs: standard 2-10. Available At: www.ada.org/ /media/ CODA/Files/pde.pdflla=en. Accessed 5 Apr. 2018

[3]. Liaison Committee on Medical Education. Functions and structure of a medical school: standards for accreditation of medical education programs leading to the MD degree. 2016. Available At: med.virginia.edu/ume-curriculum/wp. Last Accessed 5 Apr. 2018.

[4]. National League for Nursing. Outcomes and competencies for graduates of practical/vocational, diploma, associate degree, baccalaureate, master's, practice doctorate, and research doctorate programs in nursing. New York: National League for Nursing, 2010.

[5]. Accreditation Council for Pharmacy Education. Accreditation standards and guidelines for the professional program in pharmacy leading to the doctor of pharmacy degree: guideline 11.2. At: www.acpe-accredit.org//pdf/ FinalS2007Guidelines2.0.pdf. Accessed 5 Apr. 2018.

[6]. Ennis RH. Critical thinking: a streamlined conception. Teaching Philosophy 1991;14(1):5-25.

[7]. Tsai TH. Validating use of a critical thinking test for the Dental Admission Test. J Dent Educ 2014;78(4):552-7.

[8]. Facione PA. Critical thinking: a statement of expert consensus for purposes of educational assessment and instruction. 1990. ERIC Document Reproduction Service, No. ED 315428.

[9]. Paul R. Critical thinking: what every person needs to survive in a rapidly changing world. 2nd ed. Santa Rosa, CA: Foundation for Critical Thinking, 1992.

[10]. Lyons EM. Examining the effects of problem-based learning and NCLEXRN scores on the critical thinking skills of associate degree nursing students in a southeastern community college. Int J Nurs Educ Scholarsh 2008;5(1):1-17.

[11]. Ennis TR. Assessing and enhancing critical thinking skills: enhanced peer review (EPR) with the CAT instrument. Doctoral dissertation, 2007.

[12]. Arand JU. An investigation into problem-solving in physical therapy education: prerequisites and curriculum (critical thinking, WGCTA, GRSLSS). Doctoral dissertation, 1984.

[13]. Daiek DB. Effects of the California critical thinking skills test achievement on first semester success of summer academy students. Doctoral dissertation, 1993

[14]. Facione NC, Facione PA. The "California critical thinking skills test" and the National League for Nursing accreditation requirement in critical thinking. Millbrae, CA: California Academic Press, 1994.

[15]. Behrens PJ. The Watson-Glaser critical thinking appraisal and academic performance of diploma school students. J Nurs Educ 1996;35(1):34-6.

[16]. Beck JP. A longitudinal study of critical thinking skills in freshman nursing students. Doctoral dissertation, 1999.

[17]. Frye B, Alfred N, Campbell M. Use of the Watson-Glaser critical thinking appraisal with BSN students. Nurs Health Care Perspect 1999;20(5):253-5.

[18]. Gadzella BM, Baloglu M. Psychometric properties of Watson-Glaser critical 
thinking appraisal for a sample of education majors. Psychol Rep 2003;92(3 Pt 2):1249-54.

[19]. Huhn K, Black L, Jensen GM, Deutsch JE. Construct validity of the health science reasoning test. J Allied Health 2011;40(4):181-6.

[20]. Denny JP. The relationship between undergraduate research and critical thinking skills. Doctoral dissertation, 2012.

[21]. Bixler GM, Brown A, Way D, Ledford C, Mahan JD. Collaborative concept mapping and critical thinking in fourth-year medical students. Clinical pediatrics. 2015 Aug;54(9):833-9.

[22]. Liu O, Mao L, Frankel L, Xu J. Assessing critical thinking in higher education: the HEIghten approach and preliminary validity evidence. Assess Eval High Educ. 2016;41(5):677-94. 